The subject cropped up again on July II on a motion by the South-Eastern Federation, as follows :

That this Conference express its approval of the R.M.P.A. Cortificate as a satisfactory prool of qualification for mental nurding, owing to the hich standard of examination, its genoral acceptance by Authoritice, the reaconabloness of the cost of obtaining the same, and the fact that some Authorities would rofuse to pay the foes and bonus, and would consider instituting examinations of their own rather than submit to the imposition of the General Nursing Counell Cortificate.

Mr. Joyce (Park Prewett) : After Mr. Gibson's statement on this matter yesterday there is little I can say; in other words, he has stolen my thunder, but being the sponsor of this resolution, I must re-tread the ground. The R.M.P.A. have a high standard of curriculum, being equivalent to two theoretical examinations and a practical test held at the institution by independent examiners. It is not necessary to travel long journeys and suffer other inconveniences, apart from expenses incurred, for the purpose of sitting examinations. The fees for the R.M.P.A. examinations are quite reasonable. The passing of the final examination is a sufficient guarantee of proficiency for all who require the services of a mental nurse, whether for private or institutional nursing. It has come to my knowledge that several institutions do not pay the stipulated sums of two and three guineas, which amounts are required to cover the examination fees payable to the G.N.C. I have also been informed that several L.C.C. committees have suggested that rather than pay the amount mentioned, which in their case would run into a total of several thousand pounds per annum, they would prefer to in. stitute an examination of their own and pay their own doctors. The R.M.P.A. examinations fulfil all requirements, and with that body they are fully satisfied. We must support one body, and this Conference should finally decide whose colours they are going to fly. With the R.M.P.A. there are cheapness, convenience and status on the one hand, and with the G.N.C. high examinations fees, the inconvenience and expenses of travelling, and a degree of autocracy on the other. I venture to ask the Conference to give a final decision on the subject.

Mr. Robson (Colchester) seconded.

[The resolution was carried.

\title{
ROYAL MEDICAL BENEVOLENT FUND CHRISTMAS GIFTS.
}

To the Editor of the 'Journal of Mental Science.'

DeAr Sir, - It has been the practice of the Royal Medical Benevolent Fund for many years to give a Christmas gift to each annuitant, and some of the most necessitous of the grantees.

Both the annuitants, who are over 60 years of age, and the grantees are deprived of those little amenities of life which the more fortunate of us enjoy.

Many of our beneficiaries are alone in the world, as their friends and relations have passed over, and consequently they will not receive any gift or extra comfort this Christmas.

Last year the Fund gave to each $30 s$.; this meant an expenditure of $£ 500$. Many readers will wish that the recipients of this gift in former years should not be deprived of it this year.

But unless I am favoured by a generous response to this appeal our Funds will not allow of this gracious and friendly act.

Will every reader of this letter please consider if he or she cannot send to the Honorary Treasurer, Royal Medical Benevolent Fund, II, Chandos Street, Londan, W. I, a Xmas donation?

I shall be grateful whether the donation be large or small.

Yours faithfully,

(Sigmed) THOMAS BArLow,

President. 